\title{
Quantitative anatomy of the liver visceral surface in the human fetus
}

\author{
Monika Paruszewska-Achtel ${ }^{A-D}$, Małgorzata Dombek ${ }^{A-C}$, Mateusz Badura ${ }^{B, C}$, \\ Gabriela M. Elminowska-Wenda ${ }^{B, C}$, Marcin Wiśniewski ${ }^{B}$, Michał Szpinda ${ }^{A, D-F}$ \\ Department of Normal Anatomy, Collegium Medicum in Bydgoszcz, Nicolaus Copernicus University in Toruń, Poland \\ A - research concept and design; B - collection and/or assembly of data; C - data analysis and interpretation; \\ $D$ - writing the article; $E$ - critical revision of the article; $F$ - final approval of the article
}

Address for correspondence

Michał Szpinda

E-mail:michal.szpinda@cm.umk.pl

Funding sources

None declared

Conflict of interest

None declared

Received on March 4, 2016

Reviewed on March 26, 2017

Accepted on June 2, 2017

\begin{abstract}
Background. Understanding liver growth is relevant in both determining the status of normative fetal development and prenatal detection of its disorders.
\end{abstract}

Objectives. This study attempted to examine age-specific reference intervals and the best-fit growth dynamics of the liver visceral surface for hepatic height, length, isthmic diameter, oblique diameters, circumferences of individual lobes, and total liver circumference.

Material and methods. Using anatomical, digital and statistical methods, the liver visceral surface was measured in 69 human fetuses of both sexes (32 males and 37 females) aged 18-30 weeks, derived from spontaneous abortions and stillbirths.

Results. The statistical analysis showed no sex differences. The best growth models mostly followed natural logarithmic functions, except for the length of the fissure for ligamentum teres hepatis and the length of fossa for gallbladder, which increased commensurately. Neither the length of fissure for ductus venosus nor the length of sulcus for inferior vena cava modeled the best-fit curves. The vertical-to-transverse diameter ratio of the liver was constant and averaged $0.75 \pm 0.12$, while the isthmus ratio significantly altered from $0.78 \pm 0.07$ at $18-19$ weeks through $0.68 \pm 0.05$ at $26-27$ weeks to $0.72 \pm 0.07$ at $28-30$ weeks of gestation.

Conclusions. With no sexual differences, the liver morphometric parameters increased either logarithmically (lengths of: transverse diameter, vertical diameter, right oblique diameter, left oblique diameter, isthmic diameter and porta hepatis, circumferences of: right lobe, left lobe, quadrate lobe, caudate lobe, and total liver circumference) or proportionately (length of fissure for ligamentum teres hepatis, length of fossa for gallbladder). The quantitative data of the growing liver may be relevant in both the ultrasound monitoring of fetuses and early detection of congenital liver anomalies.

Key words: liver, human fetus, size, visceral surface, growth dynamics

DOI

10.17219/acem/74375

\section{Copyright}

Copyright by Author(s)

This is an article distributed under the terms of the

Creative Commons Attribution Non-Commercial License

(http://creativecommons.org/licenses/by-nc-nd/4.0/) 


\section{Introduction}

Liver size is a beneficial parameter in the diagnosis and monitoring of intrauterine growth retardation (IUGR), as well as in determining the status of fetal growth. ${ }^{1-4}$ Its abnormal size may result from maternal gestational diabetes, isoimmunization, intrauterine infections, heart malformations, tumors, some metabolic diseases, and either microsomia or macrosomia. ${ }^{5-9}$ The fetal liver is the very first organ to reveal an abnormal pregnancy. ${ }^{10}$ Reduction in liver size may be caused by IUGR, fetal erythroblastosis, anemia, thalassemia, and disturbances in the transport of oxygen with Bart's hemoglobin. ${ }^{11-14}$ According to Fleischer et al., liver size is a good indicator of clinical pregnancies complicated by serological conflicts. ${ }^{5}$ As a useful reference parameter for ultrasound examination, liver size provides us with quantitative and qualitative information concerning both liver structure and function. ${ }^{15}$ Both autopsy examinations and modern in utero imaging techniques provide suitable quantitative evidence about fetal growth and organ development. ${ }^{16}$ Knowledge on the normative liver growth is relevant in monitoring normal development and plays an essential role in prenatal detection of its malformations. ${ }^{17}$

To date, however, apart from anatomical research on the quantitative analysis of the fetal liver performed by Albay et al., no nomograms concerning its visceral surface have been computed. ${ }^{12}$ Thus, in the present study we aimed to examine the liver visceral surface, as follows:

- age-specific reference intervals with respect to gestational age of the 15 linear hepatic dimensions (height, length, right and left oblique diameters, isthmic diameter, length of fissure for ligamentum teres hepatis, length of fissure for ductus venosus, length of fossa for gallbladder, length of sulcus for inferior vena cava, and length of porta hepatis, as well as circumferences of 4 individual lobes and total circumference);

- possible sex differences in the parameters studied;

- the best-fit growth curves for each morphometric parameter studied;

- the relative growth dynamics of the fetal liver (transverse-to-vertical diameter ratio, isthmus ratio).

\section{Material and methods}

The research material consisted of 69 human fetuses of both sexes (32 males and 37 females) aged from 18 to 30 weeks, of Caucasian ethnic origin (Table 1), collected at the Department of Normal Anatomy of our university (Collegium Medicum in Bydgoszcz, Nicolaus Copernicus University in Toruń, Poland). All samples had been gathered between the years 1989 and 1999 from spontaneous abortions or stillbirths, and then preserved in neutral formalin solution. Legal and ethical issues were approved by the University Research Ethics Committee (reference: KB 161/2013). Fetal
Table 1. Distribution of the fetuses examined

\begin{tabular}{|c|c|c|c|c|c|c|}
\hline \multirow{2}{*}{$\begin{array}{c}\text { Fetal age } \\
\text { [weeks] }\end{array}$} & \multicolumn{2}{|c|}{ Crown-rump length $[\mathrm{mm}]$} & \multicolumn{3}{|c|}{ Sex } \\
\cline { 2 - 4 } & median & $\min$ & $\max$ & & males & females \\
\hline 18 & 139.5 & 131.0 & 143.0 & 4 & 3 & 1 \\
\hline 19 & 152.5 & 145.0 & 155.0 & 6 & 4 & 2 \\
\hline 20 & 161.0 & 159.0 & 167.0 & 7 & 3 & 4 \\
\hline 21 & 175.0 & 170.0 & 180.0 & 7 & 5 & 2 \\
\hline 22 & 185.5 & 181.0 & 190.0 & 6 & 1 & 5 \\
\hline 24 & 199.5 & 195.0 & 204.0 & 6 & 4 & 2 \\
\hline 25 & 212.0 & 205.0 & 214.0 & 10 & 2 & 8 \\
\hline 26 & 215.0 & 215.0 & 220.0 & 5 & 2 & 3 \\
\hline 27 & 240.5 & 235.0 & 242.0 & 4 & 2 & 2 \\
\hline 28 & 253.0 & 247.0 & 253.0 & 7 & 1 & 6 \\
\hline 30 & 264.0 & 263.0 & 265.0 & 4 & 4 & 0 \\
\hline
\end{tabular}

For anatomists dealing with fetuses, the most objective information for establishing fetal ages is the crown-rump length, when compared to the known data of the beginning of the last maternal menstrual period or to ultrasonic measurements of head circumference, bi-parietal diameter, occipitofrontal diameter, abdominal circumference, and femur length.

age determination was based on the crown-rump length (CRL), known date of the $1^{\text {st }}$ day of the maternal menstrual period, and the 5 fetal anthropometric measurements (head circumference, bi-parietal diameter, occipitofrontal diameter, abdominal circumference, and femur length) assessed by early $2^{\text {nd }}$ trimester ultrasound scans. ${ }^{18-26}$ As a prerequisite, we excluded fetuses with chromosomal abnormalities or intrauterine growth restriction, as well as from multiple pregnancies, from diabetic mothers and those with severe infections.

\section{Anatomical method}

After having been fixed in $10 \%$ formalin solution for 12-24 months, fetuses were anatomically dissected through median and transverse laparotomy with the removal of the liver. Since no liver malformations were macroscopically perceived in the individuals studied, the examined sample could rightly be considered normal.

\section{Digital image analysis}

The visceral surface of each isolated liver with a millimeter scale was placed vertically to the optical lens axis, recorded with the use of a Canon 550D camera (Canon, Inc., Tokyo, Japan) and digitalized to TIFF images (Fig. 1). Next the morphometric measurements were performed using the digital image analysis system of NIS-Elements AR 3.0 (Nikon Corporation, Tokyo, Japan), with the greatest accuracy to the nearest $0.01 \mathrm{~mm}$. In each specimen, the following 15 measurements in mm (Fig. 2 A-F) and 2 calculations on the visceral surface of the liver were performed: 


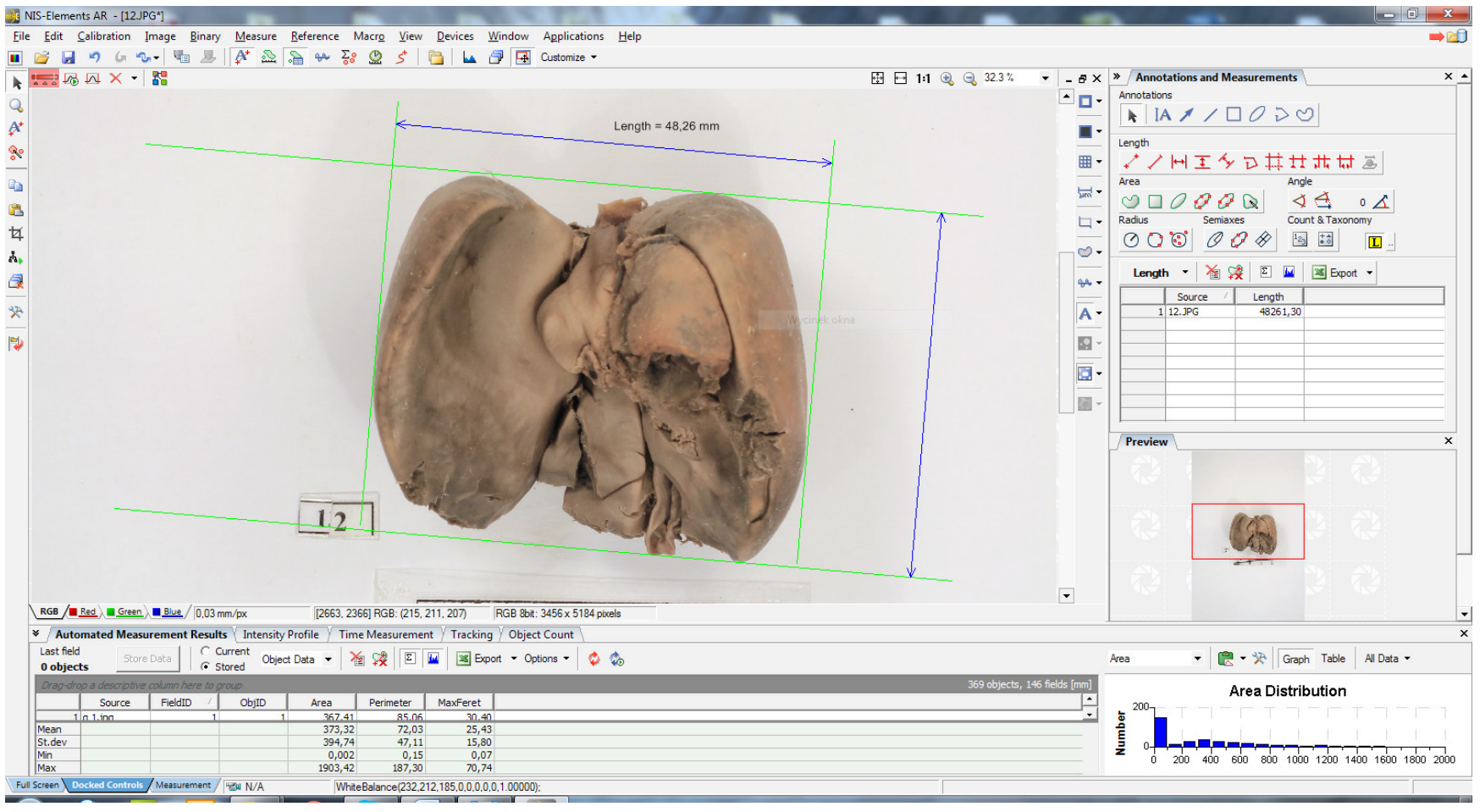

Fig. 1. A screen of digital image analysis of NIS Elements AR 3.0 (Nikon Corporation, Tokyo, Japan) while assessing the transverse and vertical diameters

- transverse diameter of the liver, corresponding to the greatest horizontal distance of the liver between its right and left borderlines (Fig. 2 B);

- vertical diameter of the liver, corresponding to the greatest vertical distance of the liver between its superior and inferior borderlines (Fig. 2 B);

- isthmic diameter of the liver, corresponding to the shortest horizontal distance of the liver between its right and left borderlines (Fig 2 B);

- right oblique diameter, corresponding to the longest oblique distance of the liver between its uppermost point of the right borderline to the lowermost point of the left borderline (Fig. 2 C);

- left oblique diameter, corresponding to the longest oblique distance of the liver between its uppermost point of the left borderline to the lowermost point of the right borderline (Fig. $2 \mathrm{C}$ );

- length of fissure for ligamentum teres hepatis (Fig. 2 D);

- length of fissure for ductus venosus (Fig. 2 D);

- length of fossa for gallbladder (Fig. 2 D);

- length of sulcus for inferior vena cava (Fig. 2 D);

- length of porta hepatis (Fig. 2 D);

- circumference of right lobe (Fig. 2 E);

- circumference of left lobe (Fig. 2 E);

- circumference of quadrate lobe (Fig. 2 E);

- circumference of caudate lobe (Fig. 2 E);

- total liver circumference (Fig. 2 F);

- transverse-to-vertical ratio, corresponding to a quotient of the transverse diameter to the vertical diameter;

- isthmus ratio, corresponding to a quotient of the isthmus diameter to the vertical diameter.

\section{Statistical analysis}

All measurements were done by 2 independent researchers (M.P.A., M.B.). Each measurement was performed 3 times under the same conditions, but at different times, and then averaged. The differences between repeated measurements, as the intra-observer variation, were assessed by the oneway analysis of variance (ANOVA) test for paired data and post hoc Tukey's honest significant difference (HSD) test. ${ }^{17}$ Thus, in order to examine the inter-observer reproducibility, the intra-class correlation coefficients (ICC) were calculated. In the present study, we used the STATISTICA v. 10 (StatSoft Inc., Tulsa, USA) and PQStat v. 1.6.2. (PQStat Software, Poznań, Poland) programs to analyze all the numerical data. The studied fetuses were separated into 12 1-week intervals, not equally distributed with respect to the fetal age. Obviously, some 1-week intervals did not represent adequate samples, including either 4 (fetuses aged 18, 27 and 30 weeks) or 3 (fetuses aged 26 weeks) specimens only. As the initial step, the first 4 intervals (18-21 weeks), the successive 4 intervals (22-25 weeks) and the last consecutive 4 intervals (26-30 weeks) were aggregated. To examine possible sex differences, we used the Student's t-test for the following 3 age groups: $18-21(n=24), 22-25(n=27)$ and $26-30$ $(\mathrm{n}=18)$ weeks. The one-way ANOVA test for unpaired data and post hoc Tukey's honest significant difference (HSD) test were used for the 3 aforementioned age groups to check whether or not significant differences existed with age. Furthermore, to choose the best-fit curve for each parameter vs gestational age, the highest coefficient of determination $\left(R^{2}\right)$ was selected, and then the linear or nonlinear regression 
A

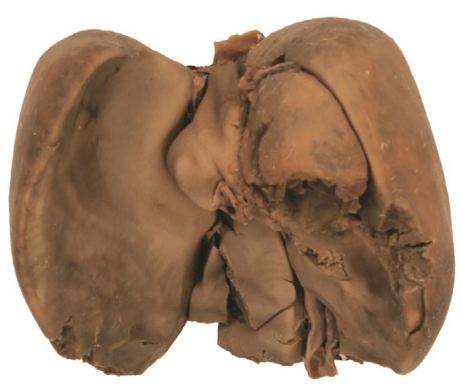

C

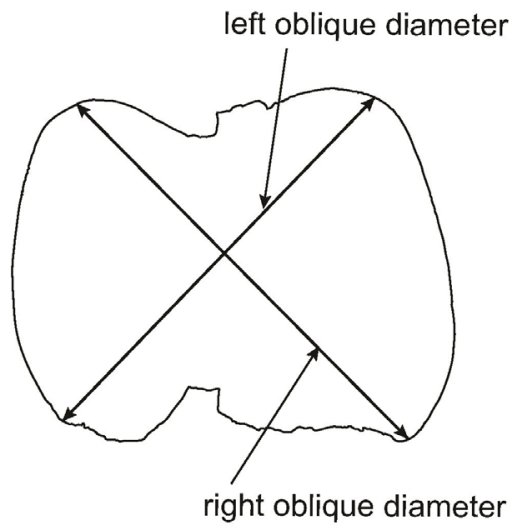

$E$

left lobe circumference

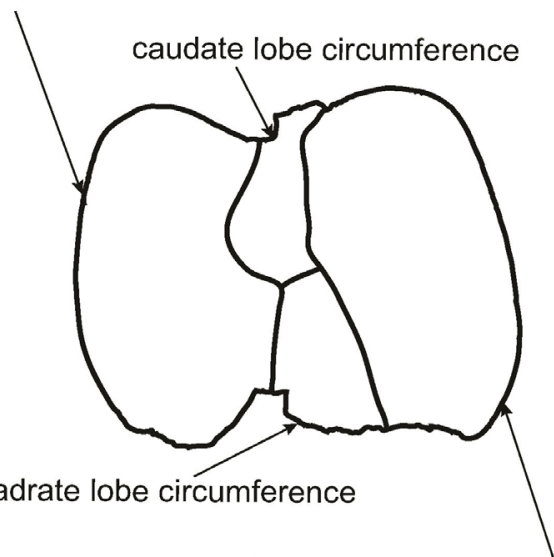

right lobe circumference
B

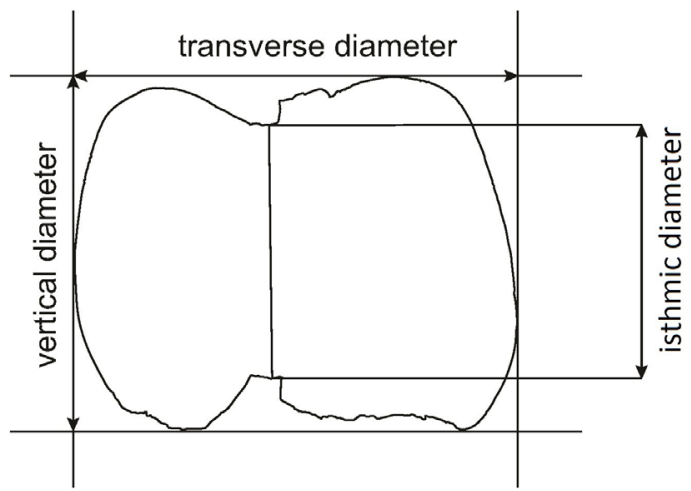

D

length of fissure for ductus venosus

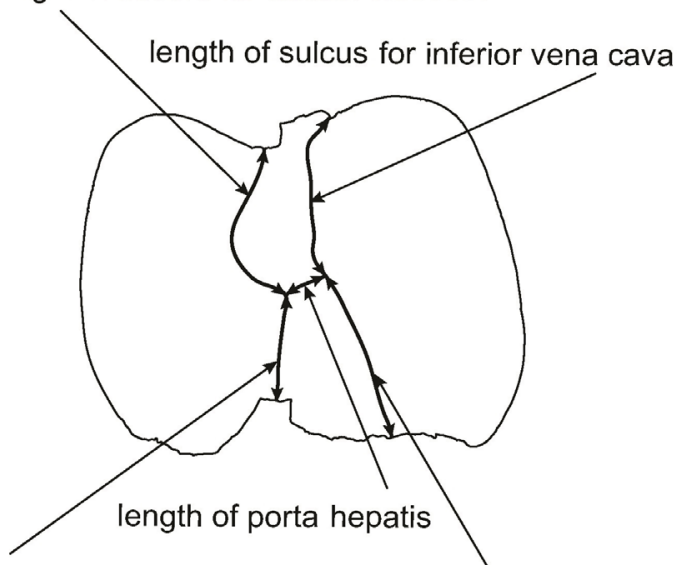

length of fissure for ligamentum teres hepatis

length of fossa for gallbladder

$\mathrm{F}$

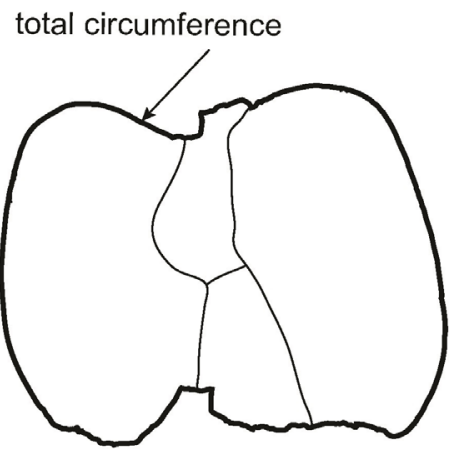

Fig. 2. Measurements of the fetal liver on its visceral surface in a female fetus aged 23 weeks (A)

B - transverse, vertical and isthmic diameters; C - right and left oblique diameters; D - lengths of fissure for ligamentum teres hepatis, fissure for ductus venosus, fossa for gallbladder, sulcus for inferior vena cava, and porta hepatis; E - circumferences of the liver lobes; F - total liver circumference. 
analysis was computed. The relative liver growth was estimated as the transverse-to-vertical ratio and the isthmus ratio. A p-value $<0.05$ was considered statistically significant.

\section{Results}

No statistically significant differences were found in assessing both the intra-observer and inter-observer reproducibility of liver measurements ( $\mathrm{p}>0.05$ ). As displayed in Table 2, the ICC calculated with respect to 2 independent observers were statistically significant $(\mathrm{p}<0.0001)$ and of excellent reproducibility. The individual morphometric values obtained were characterized by the normality of distribution and homogeneity of variance. Due to this, quantitative variables were expressed as mean \pm standard deviation (SD). The statistical analysis of numerical data showed no significant differences between male and female fetuses (Table 3). As a result, all individual parameters have been displayed aggregately for the entire sample (Tables 4-6).

The best growth models for the parameters studied along with their $\mathrm{R}^{2}$ values were displayed in Table 7.

In order to objectify the obtained measurements in fetuses of different age, we calculated the relative growth of the liver as both the transverse-to-vertical diameter ratio and isthmus ratio. The transverse-tovertical diameter ratio reached the value of $0.75 \pm 0.12$, while the isthmus ratio significantly altered from $0.78 \pm 0.07$ at $18-19$ weeks through $0.68 \pm 0.05$ at $26-27$ weeks to $0.72 \pm 0.07$ at $28-30$ weeks of gestation.

Table 2. Intra-class correlation coefficient (ICC) values for inter-observer reproducibility

\begin{tabular}{|l|c|}
\multicolumn{1}{|c|}{ Parameter } & ICC $(2,1)$ \\
\hline Transverse diameter & $0.999^{*}$ \\
\hline Vertical diameter & $0.998^{*}$ \\
\hline Right oblique diameter & $0.998^{*}$ \\
\hline Left oblique diameter & $0.999^{*}$ \\
\hline Isthmic diameter & $0.997^{*}$ \\
\hline Length of fissure for ligamentum teres hepatis & $0.994^{*}$ \\
\hline Length of fissure for ductus venosus & $0.986^{*}$ \\
\hline Length of fossa for gallbladder & $0.995^{*}$ \\
\hline Length of sulcus for inferior vena cava & $0.990^{*}$ \\
\hline Porta hepatis & $0.979^{*}$ \\
\hline Right lobe circumference & $1.000^{*}$ \\
\hline Left lobe circumference & $1.000^{*}$ \\
\hline Quadrate lobe circumference & $0.999^{*}$ \\
\hline Caudate lobe circumference & $0.998^{*}$ \\
\hline Total liver circumference & $1.000^{*}$ \\
\hline
\end{tabular}

* statistically significant $(p<0.0001)$.

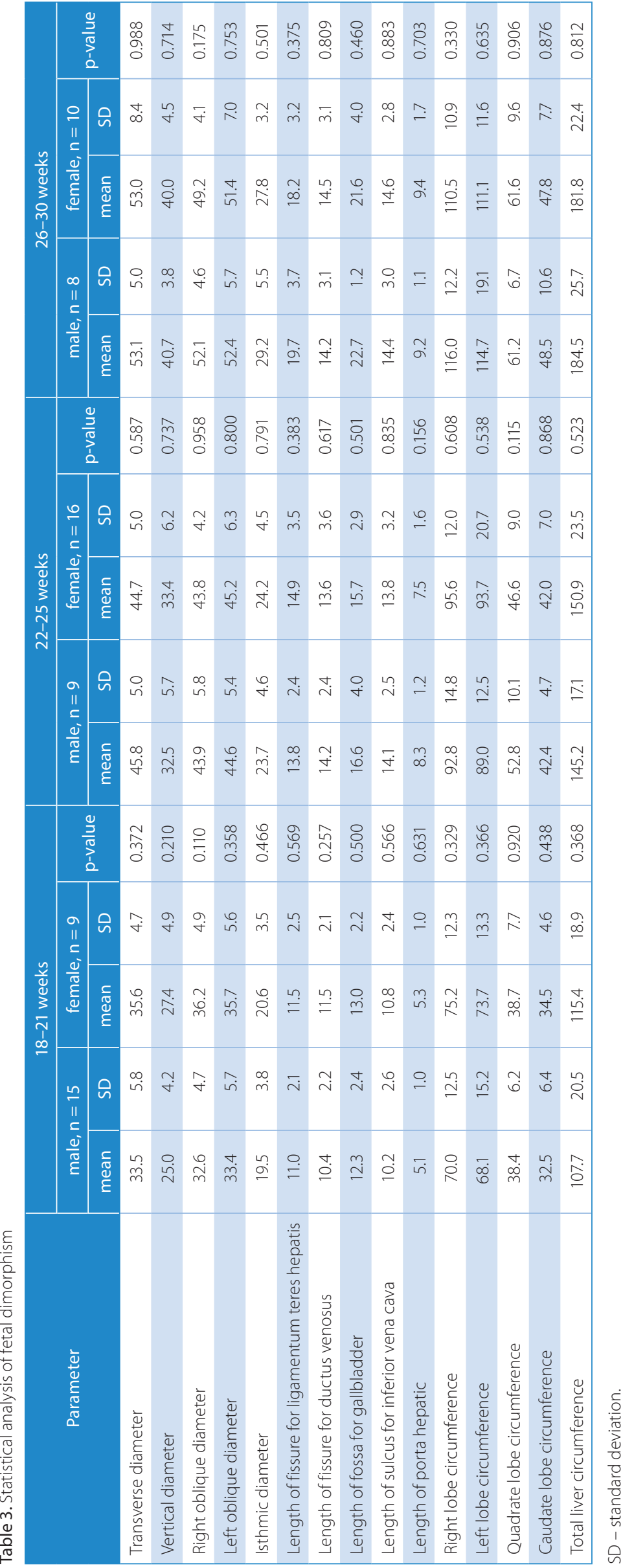


Table 4. Diameters of the growing liver in the human fetus

\begin{tabular}{|c|c|c|c|c|c|c|c|c|c|c|c|}
\hline \multicolumn{12}{|c|}{ Diameter [mm] } \\
\hline \multirow{2}{*}{$\begin{array}{c}\text { Age } \\
{[\text { weeks] }}\end{array}$} & \multirow{2}{*}{$\mathrm{n}$} & \multicolumn{2}{|c|}{ transverse } & \multicolumn{2}{|c|}{ vertical } & \multicolumn{2}{|c|}{ isthmic } & \multicolumn{2}{|c|}{ right oblique } & \multicolumn{2}{|c|}{ left oblique } \\
\hline & & mean & SD & mean & SD & mean & SD & mean & SD & mean & SD \\
\hline 18 & 4 & 29.64 & 6.21 & 21.51 & 3.84 & 15.82 & 2.63 & 29.02 & 5.10 & 29.56 & 4.92 \\
\hline 19 & 6 & 32.04 & 2.32 & 23.48 & 4.14 & 18.64 & 3.11 & 31.82 & 2.33 & 30.72 & 3.43 \\
\hline 20 & 7 & 35.22 & 4.25 & 27.69 & 3.83 & 21.37 & 3.36 & 35.64 & 5.66 & 36.50 & 4.68 \\
\hline 21 & 7 & 37.87 & 5.93 & 28.79 & 3.14 & 21.84 & 3.04 & 36.63 & 3.66 & 37.78 & 5.40 \\
\hline $18-21$ & 24 & $34.27^{(a)}$ & 5.42 & $25.93^{(a)}$ & 4.52 & $19.90^{(a)}$ & 3.67 & $33.87^{(a)}$ & 4.99 & $34.27^{(a)}$ & 5.61 \\
\hline 22 & 6 & 40.02 & 2.99 & 29.16 & 5.14 & 21.94 & 4.67 & 39.19 & 3.56 & 40.02 & 2.99 \\
\hline 23 & 6 & 44.45 & 3.71 & 33.70 & 4.25 & 23.60 & 3.83 & 43.59 & 4.83 & 44.45 & 3.71 \\
\hline 24 & 10 & 45.05 & 3.51 & 33.67 & 6.38 & 24.50 & 3.15 & 44.15 & 3.31 & 45.05 & 3.51 \\
\hline 25 & 5 & 51.89 & 2.47 & 35.86 & 6.98 & 26.34 & 6.75 & 49.21 & 2.03 & 51.89 & 2.47 \\
\hline $22-25$ & 27 & $45.07^{(b)}$ & 4.95 & $33.08^{(b)}$ & 5.95 & $24.07^{(b)}$ & 4.43 & $43.86^{(b)}$ & 4.68 & $45.07^{(b)}$ & 4.95 \\
\hline 26 & 3 & 48.99 & 0.21 & 36.92 & 2.56 & 27.07 & 0.17 & 49.37 & 3.48 & 45.07 & 2.69 \\
\hline 27 & 4 & 52.77 & 6.92 & 39.36 & 3.61 & 25.39 & 2.23 & 47.44 & 6.55 & 47.05 & 6.58 \\
\hline 28 & 7 & 54.00 & 9.22 & 41.18 & 4.79 & 29.03 & 3.40 & 50.38 & 2.79 & 52.13 & 7.30 \\
\hline 30 & 4 & 54.73 & 5.68 & 42.17 & 3.50 & 31.42 & 7.07 & 54.64 & 2.95 & 55.84 & 4.76 \\
\hline $26-30$ & 18 & $53.05^{(c)}$ & 6.93 & $40.29^{(c)}$ & 4.09 & $28.43^{(c)}$ & 4.30 & $50.50^{(c)}$ & 4.44 & $51.82^{(\mathrm{c})}$ & 6.26 \\
\hline \multicolumn{2}{|l|}{ (a) vs (b) } & \multicolumn{2}{|c|}{$p<0.001$} & \multicolumn{2}{|c|}{$p<0.001$} & \multicolumn{2}{|c|}{$p<0.01$} & \multicolumn{2}{|c|}{$p<0.001$} & \multicolumn{2}{|c|}{$p<0.001$} \\
\hline \multicolumn{2}{|l|}{ (a) vs (c) } & \multicolumn{2}{|c|}{$p<0.001$} & \multicolumn{2}{|c|}{$p<0.001$} & \multicolumn{2}{|c|}{$p<0.001$} & \multicolumn{2}{|c|}{$p<0.001$} & \multicolumn{2}{|c|}{$p<0.001$} \\
\hline \multicolumn{2}{|l|}{ (b) vs (c) } & \multicolumn{2}{|c|}{$p<0.001$} & \multicolumn{2}{|c|}{$p<0.001$} & \multicolumn{2}{|c|}{$p<0.01$} & \multicolumn{2}{|c|}{$p<0.001$} & \multicolumn{2}{|c|}{$p<0.01$} \\
\hline
\end{tabular}

Means between the 3 age groups of 18-21, 22-25 and 26-30 weeks, marked by letters (a), (b) and (c) differ significantly (in bold). SD - standard deviation.

\section{Discussion}

Understanding the normative liver growth is crucial in both monitoring normal fetal development and prenatal detection of inherited faults. The present study intended to examine age-specific reference intervals and growth dynamics which are best-fit for the gestational age with respect to the linear dimensions of the liver measured on its visceral surface. Apart from that, we attempted to present their relative growth by introducing 2 liver ratios, namely the transverse-to-vertical diameter ratio and the isthmus ratio.

We considered the data obtained in the current examination to be both normative and factual. This statement results from the following 3 reasons. Firstly, the fetal sample presented neither explicit, extrinsic, nor intrinsic malformations. Secondly, the material under examination was comparable, because the fetuses had been immersed in formalin solution for 15-20 years. According to the professional literature, shrinkage in formalin did not exceed $1 \%$ with reference to any linear dimension of the liver. ${ }^{18-27}$ Furthermore, the size of the liver in situ was virtually unfettered by formalin solution, since some liver linear dimensions, i.e., height, as well as transverse and sagittal diameters, achieved in the present series, accurately corresponded with those obtained by Chang et al., when measuring in utero fetuses of the same age with the use of $3 \mathrm{D}$-ultrasound. ${ }^{3}$ Thirdly, in order to measure the liver parameters, an optimized digital image system (NIS-Elements AR 3.0.; Nikon) was used. It is noteworthy that digital image analysis is an objective method to quantitatively assess the growing liver. Notably, all the studied parameters were clearly defined, outlined by a cursor and so gauged.

The present study is the first to provide objective numerical information about the visceral surface of the growing liver in human fetuses at 18-30 weeks. Since the statistical analysis did not show any sexual differences in terms of the parameters studied, our findings have been displayed aggregately without regard to sex.

To date, however, only Albay et al., on the basis of autopsied human fetuses aged 9-40 weeks, provided algebraic data concerning the linear parameters on the hepatic visceral surface, volume and weight of the liver. ${ }^{12}$ These authors found the liver width to increase from $39 \pm 12 \mathrm{~mm}$ to $67 \pm 11 \mathrm{~mm}$ in the period of 13-37 weeks. Their findings coincide with our results in the material under examination, at which the length of transverse diameter on the hepatic visceral surface increased from $29.64 \pm 6.21$ in a 18 -week fetus to $54.73 \pm 5.68 \mathrm{~mm}$ in a 30 -week fetus. Also, in the fetuses aged 13-37 weeks, Albay et al. revealed an increase in liver height from $25 \pm 8 \mathrm{~mm}$ to $41 \pm 7 \mathrm{~mm} .^{12}$ This parameter turned out to be equal to our liver vertical diameter, which increased from $21.51 \pm 3.84 \mathrm{~mm}$ to $42.17 \pm 3.50 \mathrm{~mm}$. Of note, we found both the liver 
Table 5. Lengths of the growing liver in the human fetus

\begin{tabular}{|c|c|c|c|c|c|c|c|c|c|c|c|}
\hline \multicolumn{12}{|c|}{ Length [mm] } \\
\hline \multirow{2}{*}{$\begin{array}{c}\text { Age } \\
\text { [weeks] }\end{array}$} & \multirow{2}{*}{$n$} & \multicolumn{2}{|c|}{$\begin{array}{l}\text { fissure for ligamentum } \\
\text { teres hepatis }\end{array}$} & \multicolumn{2}{|c|}{$\begin{array}{l}\text { fissure for ductus } \\
\text { venosus }\end{array}$} & \multicolumn{2}{|c|}{ fossa for gallbladder } & \multicolumn{2}{|c|}{$\begin{array}{c}\text { sulcus for inferior vena } \\
\text { cava }\end{array}$} & \multicolumn{2}{|c|}{ porta hepatis } \\
\hline & & mean & SD & mean & SD & mean & SD & mean & SD & mean & SD \\
\hline 18 & 4 & 9.42 & 1.48 & 8.89 & 2.15 & 11.25 & 1.89 & 7.42 & 1.05 & 4.60 & 0.96 \\
\hline 19 & 6 & 10.50 & 2.03 & 9.69 & 1.49 & 11.19 & 2.41 & 9.34 & 1.97 & 4.98 & 1.07 \\
\hline 20 & 7 & 11.72 & 2.67 & 12.18 & 1.53 & 13.29 & 2.22 & 12.07 & 1.52 & 5.13 & 0.60 \\
\hline 21 & 7 & 12.25 & 1.73 & 11.51 & 2.17 & 13.82 & 1.73 & 11.52 & 2.50 & 5.65 & 1.20 \\
\hline $18-21$ & 24 & $11.19^{(a)}$ & 2.22 & $10.81^{(a)}$ & 2.15 & $12.58^{(a)}$ & 2.29 & $10.45^{(a)}$ & 2.50 & $5.15^{(a)}$ & 0.99 \\
\hline 22 & 6 & 12.96 & 2.43 & 12.11 & 1.87 & 12.70 & 1.99 & 11.86 & 2.87 & 7.53 & 1.56 \\
\hline 23 & 6 & 12.97 & 2.14 & 14.71 & 2.58 & 16.71 & 2.73 & 15.26 & 2.26 & 7.98 & 1.14 \\
\hline 24 & 10 & 15.32 & 2.94 & 14.37 & 3.28 & 16.05 & 2.25 & 14.52 & 2.34 & 7.82 & 1.82 \\
\hline 25 & 5 & 16.76 & 4.07 & 13.58 & 4.83 & 19.08 & 3.57 & 13.60 & 4.05 & 7.64 & 1.34 \\
\hline $22-25$ & 27 & $14.54^{(b)}$ & 3.15 & $13.80^{(b)}$ & 3.30 & $16.01^{(b)}$ & 3.22 & $13.92^{(b)}$ & 2.92 & $7.76^{(b)}$ & 1.47 \\
\hline 26 & 3 & 18.03 & 0.50 & 14.23 & 3.18 & 20.84 & 0.65 & 12.10 & 2.10 & 8.29 & 0.90 \\
\hline 27 & 4 & 15.73 & 3.12 & 14.00 & 2.87 & 20.13 & 2.63 & 15.50 & 4.09 & 9.78 & 2.33 \\
\hline 28 & 7 & 19.66 & 2.28 & 14.51 & 3.26 & 22.96 & 4.15 & 14.11 & 1.96 & 9.16 & 1.21 \\
\hline 30 & 4 & 21.36 & 4.77 & 14.59 & 3.86 & 23.38 & 1.22 & 15.93 & 2.77 & 9.86 & 0.70 \\
\hline $26-30$ & 18 & $18.89^{(c)}$ & 3.43 & $14.37^{(b)}$ & 3.01 & $22.07^{(c)}$ & 3.08 & $14.49^{(b)}$ & 2.82 & $9.31^{(\mathrm{c})}$ & 1.40 \\
\hline \multicolumn{2}{|c|}{ (a) vs (b) } & \multicolumn{2}{|c|}{$p<0.001$} & \multicolumn{2}{|c|}{$p<0.01$} & \multicolumn{2}{|c|}{$p<0.001$} & \multicolumn{2}{|c|}{$p<0.001$} & \multicolumn{2}{|c|}{$p<0.001$} \\
\hline \multicolumn{2}{|c|}{ (a) vs (c) } & \multicolumn{2}{|c|}{$p<0.001$} & \multicolumn{2}{|c|}{$p<0.01$} & \multicolumn{2}{|c|}{$p<0.001$} & \multicolumn{2}{|c|}{$p<0.001$} & \multicolumn{2}{|c|}{$p<0.001$} \\
\hline \multicolumn{2}{|c|}{ (b) vs (c) } & \multicolumn{2}{|c|}{$p<0.001$} & \multicolumn{2}{|c|}{$p>0.05$} & \multicolumn{2}{|c|}{$p<0.001$} & \multicolumn{2}{|c|}{$p>0.05$} & \multicolumn{2}{|c|}{$p<0.01$} \\
\hline
\end{tabular}

Means between the 3 age groups of 18-21, 22-25 and 26-30 weeks marked by letters (a), (b) and (c) differ significantly (in bold). SD - standard deviation.

transverse and vertical diameters to grow in accordance with logarithmic functions. Apart from the aforementioned parameters on the hepatic visceral surface, Albay et al. examined the width of the right, left, quadrate, and caudate lobes, as well as the height of the quadrate and caudate lobes at 4 age ranges: $9-12,13-25,26-37$, and $38-40$ weeks of gestation. ${ }^{12}$ However, we do not comment on these results, as we did not examine them at all.

According to Albay et al., porta hepatis did not alter its position with relation to the right and left hepatic borders. ${ }^{12}$ Instead, with relation to the superior and inferior liver borders, porta hepatis shifted cephalad. In other words, the quadrate lobe lengthened more rapidly than the caudate one. To some extent, these results remain in line with our findings in the present study, because we have corroborated a greater increase in both the length of fissure for ligamentum teres hepatis and the length of fossa for gallbladder when compared to the lengths of fissures for both ductus venosus and inferior vena cava. As ascertained in the present study, an increase in length of both the fissure for ligamentum teres hepatis and fossa for gallbladder succeeded linearly. On the contrary, the lengthening of fissures for both ductus venosus and inferior vena cava proved to be unpredictable.

The lack of numerical information concerning the oblique diameters, isthmus and circumferences of the liver given in this paper limits our debate on this subject.
In order to match the best-fit model for a particular parameter of the growing liver, we initially computed different statistically significant regressions from logarithmic and square root functions through linear and quadrate functions to different polynomial functions. After that, we compared their $\mathrm{R}^{2}$ values and finally selected the highest one. Eventually, in our study we discerned 2 disparate types of growth, presented by natural logarithmic and linear functions. A logarithmic increase indicates a gradual deceleration with age, while a linear increase is strictly commensurate. Natural logarithmic growths referred to: transverse diameter, vertical diameter, isthmus of the liver, right oblique diameter, left oblique diameter, length of fissure for ductus venosus, length of sulcus for inferior vena cava, length of porta hepatis, circumference of the right lobe, circumference of the left lobe, circumference of the quadrate lobe, circumference of the caudate lobe, and total liver circumference. On the other hand, only 2 liver parameters, i.e., length of fissure for ligamentum teres hepatis and length of fossa for gallbladder, grew linearly. The greatest $\mathrm{R}^{2}$ values were typical of the following parameters: total liver circumference $\left(R^{2}=0.83\right)$, transverse diameter $\left(R^{2}=0.77\right)$, right oblique diameter $\left(R^{2}=0.77\right)$, right lobe circumference $\left(R^{2}=0.76\right)$, left lobe circumference $\left(R^{2}=0.74\right)$, isthmic diameter $\left(R^{2}=0.74\right)$, length of fossa for gallbladder $\left(R^{2}=0.74\right)$, left oblique diameter $\left(R^{2}=0.72\right)$, 
and vertical diameter $\left(R^{2}=0.71\right)$. The intermediate values of $R^{2}$ were typical of the length of porta hepatis $\left(R^{2}=0.68\right)$, and the length of fissure for ligamentum teres hepatis $\left(R^{2}=0.64\right)$ and quadrate lobe circumference $\left(R^{2}=0.64\right)$. The lowest $R^{2}$ values were characterized by caudate lobe circumference $\left(R^{2}=0.58\right)$. Because of a great interindividual variability we did not manage to match any growth curves for the lengths of fissure for ductus venosus and of sulcus for inferior vena cava.
In the current study, we found no shape variation of the liver. In this aspect, our research does not correspond with the observations made by Albay et al., who perceived the 4 different shapes of the fetal liver: squared, trapezoid, rectangular, and triangular. ${ }^{12}$ Furthermore, we observed no liver malformations, similarly to Haffajee et al. and Wang et al. ${ }^{28,29}$ These authors reported relevant cases of the fetal liver beyond week 17 with the gallbladder completely covered with hepatic parenchyma.

Table 6. Circumferences of the growing liver in the human fetus

\begin{tabular}{|c|c|c|c|c|c|c|c|c|c|c|c|}
\hline \multicolumn{12}{|c|}{ Circumference [mm] } \\
\hline \multirow{2}{*}{$\begin{array}{c}\text { Age } \\
\text { [weeks] }\end{array}$} & \multirow{2}{*}{$\mathrm{n}$} & \multicolumn{2}{|c|}{ right lobe } & \multicolumn{2}{|c|}{ left lobe } & \multicolumn{2}{|c|}{ quadrate lobe } & \multicolumn{2}{|c|}{ caudate lobe } & \multicolumn{2}{|c|}{ total } \\
\hline & & mean & SD & mean & SD & mean & $\mathrm{SD}$ & mean & SD & mean & SD \\
\hline 18 & 4 & 60.45 & 11.52 & 55.67 & 12.58 & 35.43 & 2.26 & 27.04 & 7.00 & 91.15 & 16.17 \\
\hline 19 & 6 & 65.92 & 10.73 & 61.03 & 6.22 & 37.93 & 6.36 & 31.89 & 4.21 & 98.86 & 9.24 \\
\hline 20 & 7 & 77.40 & 10.32 & 76.17 & 11.25 & 37.05 & 8.89 & 36.37 & 3.79 & 117.65 & 16.09 \\
\hline 21 & 7 & 78.15 & 11.02 & 80.31 & 13.32 & 42.34 & 5.16 & 34.85 & 5.67 & 124.66 & 19.39 \\
\hline $18-21$ & 24 & $71.92^{(a)}$ & 12.45 & $70.18^{(a)}$ & 14.45 & $38.54^{(\mathrm{a})}$ & 6.62 & $33.25^{(a)}$ & 5.77 & $110.58^{(a)}$ & 19.88 \\
\hline 22 & 6 & 83.24 & 9.08 & 78.37 & 9.99 & 40.68 & 5.76 & 38.62 & 5.86 & 128.23 & 7.35 \\
\hline 23 & 6 & 95.88 & 11.12 & 89.03 & 16.34 & 51.45 & 10.87 & 41.61 & 6.29 & 145.45 & 13.96 \\
\hline 24 & 10 & 94.51 & 10.56 & 95.79 & 18.12 & 47.93 & 8.50 & 42.36 & 3.00 & 151.03 & 20.39 \\
\hline 25 & 5 & 107.24 & 12.80 & 105.04 & 20.77 & 56.23 & 8.51 & 46.42 & 9.81 & 174.01 & 16.68 \\
\hline $22-25$ & 27 & $94.66^{(b)}$ & 12.82 & $92.13^{(b)}$ & 18.27 & $48.64^{(b)}$ & 9.64 & $42.11^{(b)}$ & 6.21 & $148.98^{(b)}$ & 21.42 \\
\hline 26 & 3 & 103.55 & 6.23 & 98.28 & 11.23 & 61.24 & 3.56 & 41.69 & 4.32 & 159.16 & 6.23 \\
\hline 27 & 4 & 109.03 & 16.27 & 106.28 & 11.12 & 55.71 & 9.81 & 46.66 & 7.72 & 173.25 & 24.51 \\
\hline 28 & 7 & 114.41 & 6.64 & 115.21 & 10.16 & 63.53 & 9.16 & 48.46 & 7.97 & 188.07 & 18.58 \\
\hline 30 & 4 & 121.29 & 12.76 & 125.59 & 19.11 & 63.61 & 7.21 & 53.60 & 12.52 & 201.89 & 22.70 \\
\hline $26-30$ & 18 & $112.93^{(c)}$ & 11.49 & $112.71^{(\mathrm{c})}$ & 15.02 & $61.43^{(\mathrm{c})}$ & 8.24 & $48.07^{(c)}$ & 8.81 & $183.03^{(\mathrm{c})}$ & 23.25 \\
\hline \multicolumn{2}{|l|}{ (a) vs (b) } & \multicolumn{2}{|c|}{$p<0.001$} & \multicolumn{2}{|c|}{$p<0.001$} & \multicolumn{2}{|c|}{$p<0.001$} & \multicolumn{2}{|c|}{$p<0.001$} & \multicolumn{2}{|c|}{$p<0.001$} \\
\hline \multicolumn{2}{|l|}{ (a) vs (c) } & \multicolumn{2}{|c|}{$p<0.001$} & \multicolumn{2}{|c|}{$p<0.001$} & \multicolumn{2}{|c|}{$p<0.001$} & \multicolumn{2}{|c|}{$p<0.001$} & \multicolumn{2}{|c|}{$p<0.001$} \\
\hline \multicolumn{2}{|l|}{ (b) vs (c) } & \multicolumn{2}{|c|}{$p<0.001$} & \multicolumn{2}{|c|}{$p<0.001$} & \multicolumn{2}{|c|}{$p<0.001$} & \multicolumn{2}{|c|}{$p<0.05$} & \multicolumn{2}{|c|}{$p<0.001$} \\
\hline
\end{tabular}

Means between the 3 age groups of 18-21, 22-25 and 26-30 weeks marked by letters ${ }^{\text {(a) }}$, (b) and (c) differ significantly (in bold). SD - standard deviation.

Table 7. The best-fit regression formulas for the fetal liver

\begin{tabular}{|c|c|c|c|c|}
\hline Parameter & Regression formula & $\mathrm{R}^{2}$ value & $\mathrm{F}$ & $p$-value \\
\hline Transverse diameter & $y=-125.518+53.754 \times \ln ($ Age $) \pm 4.198$ & 0.77 & 219.31 & $<0.001$ \\
\hline Vertical diameter & $y=-98.969+41.840 \times \ln ($ Age $) \pm 3.911$ & 0.71 & 161.85 & $<0.001$ \\
\hline Right oblique diameter & $y=-110.111+48.557 \times \ln ($ Age $) \pm 3.721$ & 0.77 & 227.02 & $<0.001$ \\
\hline Left oblique diameter & $y=-117.329+50.964 \times \ln ($ Age $) \pm 4.597$ & 0.72 & 169.75 & $<0.001$ \\
\hline Isthmic diameter & $y=-53.900+24.693 \times \ln ($ Age $) \pm 3.205$ & 0.74 & 80.01 & $<0.001$ \\
\hline Length of fissure for ligamentum teres hepatis & $y=-8.733+0.996 \times$ Age \pm 2.513 & 0.64 & 115.67 & $<0.001$ \\
\hline Length of fossa for gallbladder & $y=-9.387+1.095 \times$ Age \pm 2.220 & 0.74 & 184.09 & $<0.001$ \\
\hline Porta hepatis & $y=-26.986+10.870 \times \ln ($ Age $) \pm 1.115$ & 0.68 & 131.28 & $<0.001$ \\
\hline Right lobe circumference & $y=-287.401+120.550 \times \ln ($ Age $) \pm 10.003$ & 0.76 & 206.38 & $<0.001$ \\
\hline Left lobe circumference & $y=-295.715+122.097 \times \ln ($ Age $) \pm 10.450$ & 0.74 & 181.63 & $<0.001$ \\
\hline Quadrate lobe circumference & $y=-144.413+61.299 \times \ln ($ Age $) \pm 6.670$ & 0.64 & 116.44 & $<0.001$ \\
\hline Caudate lobe circumference & $y=-100.827+45.013 \times \ln ($ Age $) \pm 5.415$ & 0.58 & 86.16 & $<0.001$ \\
\hline Total liver circumference & $y=-517.502+210.340 \times \ln ($ Age $) \pm 13.714$ & 0.83 & 317.38 & $<0.001$ \\
\hline
\end{tabular}

$F$ - critical value; $R^{2}$ - coefficient of determination. 


\section{Conclusions}

The visceral liver surface reveals no sexual dimorphism in terms of its morphometric parameters.

The majority of the liver linear dimensions follow natural logarithmic functions, whereas the 2 linear dimensions (length of fissure for ligamentum teres hepatis, length of fossa for gallbladder) follow proportionately.

The transverse-to-vertical diameter ratio of the liver is relatively constant, while the isthmic ratio is unstable throughout the examined period.

The numerical data concerning the growing liver may be considered normative for particular fetal ages and relevant in both the ultrasound monitoring of in utero fetuses and early detection of inherited liver anomalies.

\section{References}

1. Murao F, Senoh D, Takamiya O, Yamamoto K, Hasegawa K, Kitao $M$. Ultrasonic evaluation of liver development in the fetus in utero. Gynecol Obstet Invest. 1989;28(4):198-201.

2. Murao F, Takamiya O, Yamamoto K, Iwanari O. Detection of intrauterine growth retardation based on measurement of size of the liver. Gynecol Obstet Invest. 1990;29(1):26-31.

3. Chang $\mathrm{CH}, \mathrm{Yu} \mathrm{CH}$, Chang FM, Ko HC, Chen HY. The assessment of normal fetal liver volume by three-dimensional ultrasound. Ultrasound Med Biol. 2003:26(6):1123-1129.

4. Pardi G, Cetin I. Human fetal growth and organ development: 50 years of discoveries. Am J Obstet Gynecol. 2006;194(4):1088-1099.

5. Fleischer AC, Manning FA, Jeanty $\mathrm{P}$, Romero R. Sonography in Obstetrics and Gynecology. Principles and Practice. $6^{\text {th }}$ ed. New York, NY: McGraw-Hill Professional; 2001:109-130,411-432.

6. Ghidini A, Sirtori M, Romero R, Yarkoni S, Solomon L, Hobbins JC. Hepatosplenomegaly as the only prenatal finding in fetus with pyruvate kinase deficiency anemia. Am J Perinatol. 1991;8(1):44-46.

7. Murao E, Takamori H, Hata K, Hata T, Kitao M. Fetal liver measurement by ultrasonography. Int J Gynecol Obstet. 1987;25(5):381-385.

8. Murao F, Takamori H, Aoki S, Hata K, Hata T, Yamamoto K. Ultrasonographic measurement of the human fetal liver in utero. Gynecol Obstet Invest. 1987;24(3):145-150.

9. Naeye RL. Infants of diabetic mothers: A quantitative, morphologic study. Pediatrics. 1965;35:980-988.

10. Vintzileos AM, Campbell WA, Storlazzi E, Mirochnick MH, Escoto DT, Nochimson DJ. Fetal liver ultrasound measurement in isoimmunized pregnancies. Obstet Gynecol. 1986;68(2):162-167.

11. Weiner S. The Isoimmunized Pregnancy. Perinatal Medicine Management of the High Risk Fetus and Neonate. $2^{\text {nd }}$ ed. Baltimore, MD: Williams and Wilkins; 1978:267-289.

12. Albay S, Mehmet A, Malas MA, Cetin E, Cankara N, Karahan N. Development of the liver during the fetal period. Saudi Med J. 2005;26(11):1710-1715.

13. Hedrick HL, Danzer E, Merchant A, et al. Liver position and lung-tohead ratio for prediction of extracorporeal membrane oxygenation and survival in isolated left congenital diaphragmatic hernia. Am J Obstet Gynecol. 2007;197(4):422.e1-4.

14. Silver RM. Fetal death. Obstet Gynecol. 2007;109(1):153-167.

15. Aviram R, Shpan DK, Markovitch O, Fishman A, Tepper R. Threedimensional first trimester fetal volumetry comparison with crown rump length. Early Hum Dev. 2004;80(1):1-5.

16. Breeze ACG, Gallagher FA, Lomas DJ, Smith GCS, Lees CC. Postmortem fetal organ volumetry using magnetic resonance imaging and comparison to organ weights at conventional autopsy. Ultrasound Obstet Gynecol. 2008;31(2):187-193.

17. Paruszewska-Achtel M. Morphometric study of the liver in human fetuses [doctoral thesis, in Polish]. Bydgoszcz, Poland: Nicolaus Copernicus University; 2014.

18. Szpinda M, Baumgart M, Szpinda A, et al. Cross-sectional study of the ossification center of the C1-S5 vertebral bodies. Surg Radiol Anat. 2013;35(5):395-402.
19. Szpinda M, Baumgart M, Szpinda A, Woźniak A, Mila-Kierzenkowska C. Cross-sectional study of the neural ossification centers of vertebrae C1-S5 in the human fetus. Surg Radiol Anat. 2013;35(8):701-711.

20. Szpinda M, Baumgart M, Szpinda A, et al. Morphometric study of the T6 vertebra and its three ossification centers in the human fetus. Surg Radiol Anat. 2013;35(10):901-916.

21. Szpinda $M$, Daroszewski $M$, Woźniak $A$, et al. Novel patterns for the growing main bronchi in the human fetus: An anatomical, digital and statistical study. Surg Radiol Anat. 2013;36(1):55-65.

22. Szpinda M, Daroszewski M, Woźniak A, Szpinda A, Mila-Kierzenkowska C. Tracheal dimensions in human fetuses: An anatomical, digital and statistical study. Surg Radiol Anat. 2012;34:317-323.

23. Szpinda M, Paruszewska-Achtel M, Woźniak A, Badura M, Mila-Kierzenkowska C, Wiśniewski M. Three-dimensional growth dynamics of the liver in the human fetus. Surg Radiol Anat. 2015;37:439-448.

24. Szpinda M, Paruszewska-Achtel M, Woźniak $A$, et al. Volumetric growth of the liver in the human fetus: An anatomical, hydrostatic, and statistical study. Biomed Res Int. 2015;2015:858162. doi: 10.1155/2015/858162

25. Szpinda M, Siedlaczek W, Szpinda A, Woźniak A, Mila-Kierzenkowska C, Wiśniewski M. Volumetric growth of the lungs in human fetuses: An anatomical, hydrostatic and statistical study. Surg Radiol Anat. 2014;36(8):813-820.

26. Bożiłow W, Sawicki K. Metody badań zmienności cech anatomicznych człowieka podczas rozwoju prenatalnego i okołoporodowego. Wrocław, Poland: Akademia Medyczna; 1980.

27. Gworys B. Problem oceny wieku u płodów inoworodków ludzkich [rozprawa habilitacyjna]. Wrocław, Poland: Akademia Medyczna; 1999.

28. Haffajee MR. The fetal gallbladder: Morphology and morphometry by microdissection. Surg Radiol Anat. 2000;22(5-6):261-270.

29. Wang BJ, Kim JH, Yu HC, Rodriguez-Vazquez JF, Murakami G, Cho BH. Fetal intrahepatic gallbladder and topographical anatomy of the liver hilar region and hepatocystic triangle. Clin Anat. 2012;25(5):619-627. 